\title{
EVALUATING ATTITUDES ABOUT AGING AND BODY COMPARISON AS MODERATORS OF THE RELATIONSHIP BETWEEN MENOPAUSAL STATUS AND DISORDERED EATING AND BODY IMAGE CONCERNS AMONG MIDDLE-AGED WOMEN
}

\author{
Katherine A. Thompson
}

\begin{abstract}
A thesis proposal submitted to the faculty at the University of North Carolina at Chapel Hill in partial fulfillment of the requirements for the degree of doctor of philosophy in the Psychology and Neuroscience Department in the Graduate School.
\end{abstract}

Chapel Hill

2017

Approved by:

Anna Bardone-Cone

Jessica Baker

Donald Baucom 
(C) 2017

Katherine A. Thompson ALL RIGHTS RESERVED 


\begin{abstract}
Katherine Alice Thompson: Evaluating Attitudes About Aging And Body Comparison As Moderators Of The Relationship Between Menopausal Status And Disordered Eating And Body Image Concerns Among Middle-Aged Women

(Under the direction of Anna Bardone-Cone)
\end{abstract}

The peri-menopausal transition period may be a critical window of vulnerability for disordered eating behaviors and body image concerns. No study has examined which women may be particularly at-risk during this period. This study explored group differences in disordered eating and body image by menopausal status, and whether appearance-related aging concerns and body comparison moderated these relationships. Three hundred and ten women (ages 40-68) completed an online survey. The three menopausal status groups did not significantly differ on either disordered eating or body image concerns. Results showed a significant interaction between menopausal status and aging concerns such that at low levels of aging concerns, peri-menopausal women reported greater dietary restraint than pre-menopausal women. Finally, a significant interaction between menopausal status and body comparison indicated that among women who are high in body comparison, post-menopausal women reported significantly more dietary restraint compared to both pre- and peri-menopausal women. 


\section{TABLE OF CONTENTS}

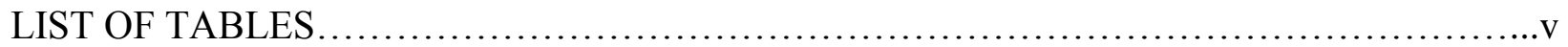

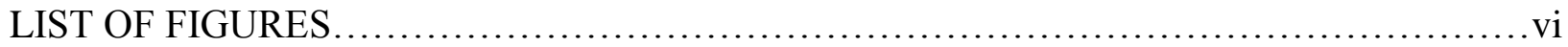

CHAPTER 1: MODERATORS OF THE RELATIONSHIP

BETWEEN MENOPAUSAL STATUS AND DISORDERED EATING

AND BODY IMAGE CONCERNS AMONG MIDDLE-AGED

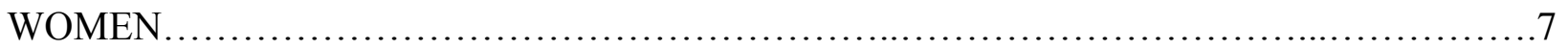

Introduction............................................................

Methods.................................................................13

Participants......................................................13

Procedure........................................................ 14

Measures............................................................. 15

Data Analytic Plan.................................................19

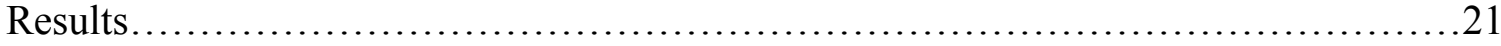

Comparison of Menopausal Groups on Disordered

Eating and Body Image Concerns................................... 21

Attitudes towards Aging Moderator Models................................21

Body Comparison Moderator Models.....................................24

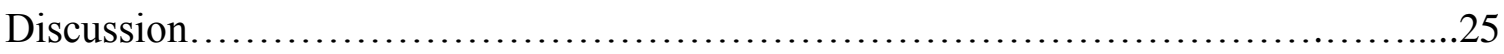

REFERENCES.............................................................. 32 


\section{LIST OF TABLES}

1. Descriptive statistics and outcome group comparisons on demographic variables........44

2. Correlations among demographic characteristics, menopause interventions, menopausal status, attitudes about aging, body comparison, disordered eating, and body image concerns ...........................46

3. Descriptive statistics of outcome variables...................................48

4. Hierarchical regression analyses of the interactions between menopausal status and attitudes about aging on women's disordered eating and body image concerns....

5. Hierarchical regression analyses of the interactions between menopausal status and body comparison on women's disordered eating and body image concerns 


\section{LIST OF FIGURES}

1. Two-way interaction involving negative attitudes about aging moderating the relationship between menopausal status and dietary restraint.

2. Two-way interaction involving negative attitudes about aging moderating the relationship between menopausal status and body image concerns.................................................... 56

3. Two-way interaction involving body comparison moderating the relationship between menopausal status and dietary restraint. 


\section{Chapter 1: Evaluating Attitudes about Aging and Body Comparison as Moderators of the Relationship between Menopausal Status and Disordered Eating Behaviors and Body Image Concerns among Middle-Aged Women}

\section{Introduction}

Past research on body image and eating disorders symptoms has focused mainly on adolescent girls and young adult women, in part because college-aged women are samples of convenience at many universities, but also because researchers believed that body image was most salient among young women (Chrisler \& Ghiz, 1993). However, recently researchers have become more interested in understanding eating disorder symptoms among middle-aged women as data suggest they are not immune to eating disorder attitudes and behaviors (Gagne et al., 2012). Approximately $4.6 \%$ of women age 40-60 meet full-threshold DSM-IV criteria for an eating disorder, while another $4.8 \%$ display subthreshold eating disorder symptoms (Mangweth-Matzek et al., 2014). Further, inpatient admissions of middle-aged women have increased between 100-400\% in recent years suggesting that eating disorders among this population may be on the rise (Cumella \& Kally, 2008; Wiseman, Sunday, Klapper, Harris, \& Halmi, 2001).

As with younger women, middle-aged women report various types of disordered eating behaviors and attitudes including: binge eating and purging behaviors (Gagne et al., 2012; Mangweth-Matzek, Hoek, \& Pope, 2014; Procopio, Holm-Denoma, Gordon, \& Joiner, 2006), body checking behaviors (Gagne et al., 2012), weight, shape, and body image concerns (Chrisler \& Ghiz, 1993; Gagne et al., 2012; Koch, Mansfield, Thurau, \& Carey, 2005; McLean, Paxton, \& 
Wertheim, 2010; Tunaley, Walsh, \& Nicolson, 1999), and restrictive dieting behaviors (Cumella \& Kally, 2008; Mangweth-Matzek et al., 2006). However, middle-aged women may also experience some unique features of eating disorder symptoms that are particularly salient for them compared to younger women. For example, in contrast to younger women with eating disorders, women who experience eating disorders later in life are more likely to experience pure restrictive behaviors and report perfectionistic attitudes and behaviors (Cumella \& Kally, 2008). Additionally, middle-aged women report greater preoccupation with food compared to their younger peers (Park \& Beaudet, 2007). Therefore, it is clear that eating disorder symptoms do exist among middle-aged women, and further, there may be some uniqueness to these symptoms during this life period.

A recent review of 61 studies examining risk factors of body image and disordered eating among middle-aged women identified three broad categories of factors: (1) psychological, (2) sociocultural, and (3) biological (Slevec \& Tiggemann, 2011). Each domain has many specific risk factors within it, some of which are risk factors that younger women experience and are affected by as well. For example, the sociocultural risk factor of self-objectification (internalizing someone else's judgment about one's body as one' s own belief) has been linked to body dissatisfaction among both young women/girls (Dakanalis et al., 2015; Slater \& Tiggemann, 2002; Tiggemann \& Slater, 2015) and middle-aged women (Grippo \& Hill, 2008; McKinley \& Lyon, 2008; Tiggemann \& Lynch, 2001). Additionally, the psychological factor of internalization of the thin beauty ideal is a strong risk factor for body dissatisfaction among both younger women (Ahern, Bennet, \& Hetherington, 2008; Guđnadóttir \& Garđarsdóttir, 2014; Keery, van den Berg, \& Thompson, 2004) and middle-aged women (Forbes et al., 2005; Matz, 
Foster, Faith, \& Wadden, 2002). However, while it is clear some risk factors are salient for both younger and older women, other risk factors may be unique to middle-aged women.

One example of a unique biological risk factor for the development of body dissatisfaction among middle-aged women is menopause. From a strictly biological perspective, menopause occurs when a woman experiences the permanent absence of a menstrual period (Kaufert et al., 1986); however, this process can take up to 5-7 years (Voda, Christy, \& Morgan, 1991). As it can be a slow and complex process, age at menopause is typically defined as the age of a women 12 months since her last menstruation (Kaufert et al., 1986). A study of women in the United States found that mean age of menopause ranges from 48 to 50 years old $(S D s=5.8$ 6.8 years depending on race and geographic location (McKnight et al., 2011). The perimenopausal phase, which is the time during which a woman transitions to menopause, centers around changes to the hormonal system (Kaufert et al., 1986) which are linked to a decreased metabolic rate. This decreased rate is, in turn, associated with both an increase in weight gain and fat mass (Ho, Wu, Chan, \& Sham, 2010), and a redistribution of body fat from the lower body (i.e., hips) to the upper body (i.e., waist and torso) (Voda et al., 1991). Women may also experience changes to skin tone/texture or an increase in facial hair as a result of menopause (Conboy, Domar, \& O’Connell, 2001; Papalia, 2007). Given that these changes to body shape, weight, and appearance are in direct contrast to Western society's young, thin, beauty standard, it is possible that menopause may be a particularly critical window of vulnerability for the development or exacerbation of disordered eating attitudes and behaviors.

Recent research has argued that the biological definition of menopause is less relevant in modern society; instead, menopause has been socially reconstructed (Utz, 2011) as women's experiences of menopause vary greatly (Daly, 1995; Flint \& Samil, 1990; Fu, Anderson, \& 
Courtney, 2003; Im, Liu, Dormire, \& Chee, 2008). In a qualitative study examining the effects of birth cohort on perceptions of menopausal experiences, Utz (2011) found that the older cohort was more accepting of menopause as an experience, while the younger cohort was more resistant and expressed a need to control the physiological changes to their bodies. The younger cohort more actively explored methods of delaying or skipping the transition compared to the older cohort. Additionally, while the older cohort consulted their doctors for research about menopause, the younger cohort consulted various sources of the media (e.g., Good Morning America) for research and discussion. For modern women, it seems menopause has become a social experience to resist.

Despite the clear implications of menopause on body weight and shape changes, few studies have examined the effects of menopausal status on body image attitudes and disordered eating behaviors. To date, only two cross-sectional studies have compared disordered eating behaviors among pre- and post-menopausal women. Data from both studies indicate that postmenopausal women report greater dietary restraint and eating disinhibition compared to premenopausal women (Copeland, Martin, Geiselman, Rash, \& Kendzor, 2006; Drobnjak, Atsiz, Ditzen, Tuschen-Caffier, \& Ehlert, 2014). However, studies evaluating body image attitudes among pre-, peri-, and post-menopausal women are less consistent. One study found that menopausal women (both peri- and post-menopausal) reported less positive attitudes about their physical appearance, and a larger body ideal, compared to pre-menopausal women (Deeks \& McCabe, 2001). However, after controlling for age, these associations became non-significant. Yet, other studies have found significant results even after controlling for age. For example, data from one cross-sectional study suggest that peri-menopausal women report a significantly greater prevalence of eating disorders, higher rates of feeling fat, and greater body shape and weight 
preoccupation compared to pre-menopausal women (Mangweth-Matzek et al., 2013). Further, prospective data indicate that pre-menopausal women report less body satisfaction compared to post-menopausal women (McLaren, Hardy, \& Kuh, 2003). Discrepancies between these results could be due to methodological differences between the studies as one was longitudinal in nature and the others were cross-sectional. The lack of consistency between results could also be due to the age variability across studies. For example, while Mangweth-Matzek et al. (2013) studied only women between the ages of 40 and 60, and McLaren et al. (2003) evaluated menopausal status at age 54, Deeks and McCabe (2001) studied women as young as 35. It is possible that studying younger women (who might be many years away from menopause) introduced a bias into their pre-menopausal condition, and that the greater variability in ages explains why their data became non-significant when accounting for age. Lastly, these discrepant results could indicate that there are important moderators not being considered in these models; interestingly, no research to date has examined moderators of the relationship between menopausal status and eating disordered attitudes and behaviors.

One potential relevant moderator is attitudes toward aging. In Western cultures, female aging has been strongly associated with a decline in physical attractiveness (Saucier, 2004). Given that middle-aged women experience physiological changes (including weight gain, wrinkles, and loss of skin elasticity) that ostensibly direct them away from the thin beauty ideal, aging anxiety is a well-studied risk factor for body shame and dissatisfaction in this age group (Gupta, 1995; Katz, 2005; Lewis \& Cachelin, 2001; McKinley \& Lyon, 2008; Midlarsky \& Nitzburg, 2008). General negative attitudes about aging have also been linked to body dissatisfaction (Halliwell \& Dittmar, 2003). Further, one study suggests that middle-aged women who subscribe to the belief that a thin body makes them look younger also have excessive 
concerns about dieting (Gupta \& Schork, 1993). Thus, negative attitudes toward aging, including aging anxiety, may be a psychological risk factor for the development of body dissatisfaction that is unique to middle-aged women.

Another potential moderator for middle-aged women is body comparison, which stems from Festinger's (1954) Social Comparison Theory. While Social Comparison Theory refers to judgments that people make regarding their own attributes compared to attributes they perceive others to have, body comparison refers specifically to comparing perceptions about one's body and physical appearance to others' (van den Berg et al., 2007). When individuals compare themselves to others they judge as "better" than themselves (engaging in "upward comparisons"), their self-evaluation can be threatened (Festinger, 1954). For example, metaanalyses show that women who observe discrepancies between their own figures and those in the media are more likely to feel dissatisfied with their weight and shape (Grabe, Ward, \& Hyde, 2008; Groesz, Levine, \& Murnen, 2002). Body comparison is associated with thin-ideal internalization, dietary restraint, and shape and weight concerns (Schaefer \& Thompson, 2014). Although body comparison has not been evaluated in the context of menopause, given the dramatic body shape and weight changes that occur, and the increasingly social experience that menopause has become, it is possible that body comparison may be a risk factor for the development of disordered eating and body image concerns during menopause.

The current study has two main goals. First, we aim to evaluate disordered eating and body image concerns among women across varying levels of menopausal status. Consistent with prior studies that suggest the peri-menopause period may be a particularly vulnerable window for eating disorders due to the dynamic changes in hormone levels relative to the greater stability of hormones during the pre- and post-menopause periods (Baker, Girdler, \& Bulik, 2012; Baker \& 
Runfola, 2016), the current study will compare disordered eating and body image concerns for women across all three levels of menopause (pre-menopause versus peri-menopause versus postmenopause). Specifically, we predict that peri-menopausal women will report more disordered eating and body image concerns compared to both the pre-menopausal and post-menopausal women. Second, we aim to identify potential moderators that could help explain who might be most at risk for an association between menopausal status and disordered eating and body image concerns. Given that data suggest that both negative attitudes toward aging and body comparison are associated with body dissatisfaction among middle-aged women (Slevec \& Tiggemann, 2011), both will be evaluated as moderators in our models. We hypothesize that the relationship between menopausal status and both disordered eating and body image concerns will be moderated by attitudes toward aging as well as body comparison. In particular, we expect that being in the transitional period of menopause (i.e., peri-menopause) will be most strongly related to body image concerns and disordered eating among those with high levels of negative attitudes about aging or high levels of body comparison.

\section{Method}

\section{$\underline{\text { Participants }}$}

We recruited 365 women between the ages of 35 and 68 years old to participate in a study of body dissatisfaction and disordered eating among three generations of women (young adult women, their mothers/middle-aged women, and their maternal grandmothers/older women). Young adult women were recruited from introductory psychology classes at a large, public, southeastern university, and their mothers, the focus of this study, were recruited using contact information provided by their daughters. A total of 369 young women participated, meaning that $99 \%$ of potential mothers participated (365 of 369 potential mothers). 
Since there were no age limits for eligibility for mothers, there was a wide range of ages present in the sample. Although there is no consensus in the literature for what age constitutes "middle-aged," prior research of mid-life or menopausal women has set a lower age limit of 40 (Bloch, 2002; Cumella \& Kally, 2008; Mangweth-Matzek et al., 2014; Porter, Penney, Russell, Russell, \& Templeton, 1996; Wing, Matthews, Kuller, Meilahn, \& Plantinga, 1991). To comply with prior research, although 365 women completed the survey, 15 mothers were excluded due to being younger than 40 years old, and two were excluded due to missing age data. Further, we also excluded 38 women who reported a surgical induction of menopause. Of note, since data suggest there may be qualitative differences in the experiences of menopause (particularly regarding physiological symptoms and psychological experiences) for women who experience menopause naturally versus via surgical-induction (Henderson \& Sherwin, 2007; Porter et al., 1996), we excluded participants who received medical intervention like the surgical removal of the ovaries or a total hysterectomy (Mangweth-Matzek et al., 2013). These exclusions for age and surgical intervention yielded a final sample of 310 women for analyses. For the remainder of this manuscript, this sample will be referred to as "middle-aged women" rather than "mothers."

The 310 participants in the final sample were an average of 50.14 years old $(S D=4.59$; range $40-68$ years). In terms of race/ethnicity, about $80 \%$ identified as White $(n=249), 10 \%$ as Asian $(n=31), 6 \%$ as Black of African American $(n=18)$, and $2 \%$ as biracial or multiracial $(n=$ 7). Mean body mass index (BMI) was $25.70 \mathrm{~kg} / \mathrm{m}^{2}\left(S D=5.88\right.$; range $\left.17.72-51.76 \mathrm{~kg} / \mathrm{m}^{2}\right)$ and, as an indication of socioeconomic status, participants had completed 16.17 years of education on average, which is the equivalent of about a 4-year college degree $(S D=2.27$; range $9-21$ years). 


\section{$\underline{\text { Procedure }}$}

Participants received an emailed link to complete a survey through Qualtrics Survey Software (Qualtrics, 2005). This email was followed up with a phone call attempt to reach potential participants, answer any questions about the study, and elicit participation. Following providing electronic consent, participants completed questionnaires assessing current menopausal status, psychological traits of attitudes toward aging and body comparison, and a variety of behaviors and attitudes related to disordered eating and body image. Total study completion time was approximately 45-60 minutes.

Compensation for the mothers/middle-aged sample involved entry into a drawing for ten \$15 gift cards; by participating, mothers also helped their daughters earn course credit. All participants were recruited and participated in the study during the spring semester of 2016, the fall semester of 2016, or the spring semester of 2017. This study was approved by the institutional review board of the University of North Carolina at Chapel Hill. $\underline{\text { Measures }}$

Demographics. Demographic data for age, highest level of education, race, ethnicity, and height and weight were collected via a set of questionnaires created for this study. Self-reported height and weight were used to calculate BMI.

Menopausal status. Women were asked to self-report their menopausal status according to the World Health Organization guidelines (World Health Organization, 1996) and definitions used in prior research (Mangweth-Matzek et al., 2013). Statuses were defined as: 1) premenopausal ("I have continued to menstruate regularly throughout the past 12 months with no change in my normal pattern - or if I do not menstruate regularly, for example, less frequently than once a month, that is due to use of hormonal contraception, being at a very low weight (e.g., 
due to anorexia nervosa), or a history of irregular periods, and not due to menopause"); 2) perimenopausal ("I have recently been missing my menstrual period or having menstrual irregularities, e.g., changes in menstrual flow, duration, or intensity lasting for at least 3 months but less than 12 months"); 3) naturally post-menopausal ("I have experienced amenorrhea, or the absence of a menstrual periods, not attributable to medical interventions for more than 12 months"); or 4) surgically post-menopausal ("I have experienced amenorrhea or the absence of a menstrual period due to medical intervention like the surgical removal of the ovaries or a total hysterectomy").

Interventions for menopause. Participants were asked "which of the following interventions have you sought to relieve the symptoms and signs of menopause (please select all that you have used at any point peri- and post-menopause)?" Response options provided include: 1) hormone therapy (e.g., Hormone Replacement Therapy/HRT), 2) vaginal estrogen, 3) lowdose antidepressants, 4) Gabapentin (Neurontin), 5) medications to prevent or treat osteoporosis, 6) other (please specify), or 7) none - I have not used any of these interventions in relation to menopause. Given the known link between certain medications (e.g., antidepressants and hormone-related medications) and disordered eating (Baker, Girdler, et al., 2012; Stunkard \& Costello Allison, 2003), use of hormone therapy, vaginal estrogen, and antidepressants was evaluated as potential covariates. For analyses, these data were coded $0=$ no interventions for menopause or an intervention other than hormone therapy, vaginal estrogen, or low-dose antidepressants, and $1=$ use of either hormone therapy, vaginal estrogen, or low-dose antidepressants.

Attitudes toward aging. Participants completed items assessing aging concerns related to physical appearance (Gupta, 1995; Gupta \& Schork, 1993). This six-item scale (e.g., "I am 
worried about the effect of aging on my appearance") is rated from $0=$ not at all to $9=$ markedly. Items are averaged with higher scores indicating more negative attitudes toward aging related to physical appearance. This scale has demonstrated convergent validity through significant, positive correlations with drive for thinness and body dissatisfaction among middleaged women (Gupta \& Schork, 1993). Coefficient alpha for the current sample was .85 .

Body comparison. The Body Comparison Orientation subscale of the Body, Eating, and Exercise Comparison Orientation Measure (Fitzsimmons-Craft, Bardone-Cone, \& Harney, 2012) was used to evaluate frequency of behaviors comparing one's physical appearance to that of same-sex peers. This six-item subscale (e.g., "I pay attention to whether or not I am as thin, or thinner, than my peers") is rated from $1=$ never to $7=$ always. Items are summed to create a total score with higher scores indicating greater tendency to engage in body comparison. This measure has demonstrated excellent internal consistency $(\alpha=.93)$, and convergent validity via significant correlations with measures of body dissatisfaction and eating disorder symptomatology ( $r$ s from .60 to .75) among young adult women (Fitzsimmons-Craft et al., 2012). Coefficient alpha for the current sample was .96 .

Disordered eating. Participants completed three measures of disordered eating. The Eating Attitudes Test - 26 (EAT-26; Garner, Olmsted, Bohr, \& Garfinkel, 1982) was used to assess a broad range of eating disorder attitudes and behaviors (e.g., "I am preoccupied with the thought of having fat on my body"). The EAT-26 is an abbreviated 26-item scale of the original 40-item Eating Attitudes Test (EAT-40; Garner \& Garfinkel, 1979). Items are scored on a 6point scale: never, rarely, sometimes, often, usually, and always. In order to compute an overall score, responses that are considered the most pathological (i.e., always) are coded as 3 . The next pathological responses are coded as 2 , with the next level of responses coded as 1 . The three 
least pathological responses are coded as 0's. The final, converted scores of 0-3 are summed with higher scores indicating greater eating pathology, and a score of 20 or more indicating a strong likelihood for a clinical eating disorder (King, 1991). The EAT-26 is highly correlated with the EAT-40 $(r=.98)$ and has demonstrated excellent internal consistency $(\alpha=.90$; Garner $\&$ Garfinkel, 1979). Coefficient alpha for the current sample was .80.

The Bulimia subscale of the Eating Disorder Inventory (EDI-Bulimia; Garner, Olmstead, \& Polivy, 1983) was used to assess bulimic symptoms using a seven-item scale (e.g., "I eat moderately in front of others and stuff myself when they're gone"). Items are scored from $1=$ never to $6=$ always. Items are summed, reflecting the common scoring method for nonclinical samples (Schoemaker, van Strien, \& van der Staak, 1994), with higher scores indicating greater bulimic pathology. The EDI-Bulimia has demonstrated good internal consistency $(\alpha=.83)$ among adult women (Clausen, Rosenvinge, Friborg, \& Rokkedal, 2011) and good convergent validity when compared to the EAT-40, another assessment of eating pathology, $(r=.88$; Garner et al., 1983). Further, the EDI-Bulimia has excellent reliability among clinical samples of women $(\alpha=.90)$. Coefficient alpha for the current sample was .85.

Lastly, the Restraint subscale from the Eating Disorder Examination-Questionnaire - 4 (EDE-Q; Fairburn \& Beglin, 1994) was used to assess the frequency of engaging in restrictive dieting behaviors (e.g., "Have you gone for long periods of time (eight or more waking hours) without eating anything at all in order to influence your shape or weight") during the past 28 days. Responses range from $0=$ no days to $6=$ every day. Items are averaged with higher scores indicating greater restraint over eating. This five-item subscale has good internal consistency $(\alpha$ $=.85)$ and two-week test-retest reliability $(r=.81)$ among adult women (Luce \& Crowther, 1999). As this measure was added to the study after the initial wave of recruitment, only women 
who participated in the study during the fall semester of 2016 and the spring semester of 2017 completed this questionnaire. Coefficient alpha for the current sample was .81 .

Body image concerns. Participants completed the Weight Concern and Shape Concern subscales of the EDE-Q (Fairburn \& Beglin, 1994) to assess their body dissatisfaction related to weight and shape. This twelve-item composite scale measures the frequency of thoughts related to concerns about body shape or weight (e.g., "Have you had a definite fear that you might gain weight?") in the past 28 days. Response options ( 0 to 6 ) are either stated as number of days ( $0=$ no days, $6=$ every day $)$ or as degree $(0=$ not at all, $6=$ markedly $)$. Items are averaged with higher scores indicating greater concern over body shape and weight. Internal consistency for the Weight Concern $(\alpha=.89)$ and Shape Concern $(\alpha=.78)$ subscales are adequate to good based on prior work among adult women (Luce \& Crowther, 1999). Consistent with past research, including a psychometric evaluation of the EDE-Q that found the weight and shape subscales

load on a single factor, weight and shape concern will be evaluated together as a single construct in the current study (Bardone-Cone, Balk, Lin, Fitzsimmons-Craft, \& Goodman, 2016; Peterson et al., 2007). Coefficient alpha for the combined body image concerns construct in the current sample was .92.

$\underline{\text { Data Analytic Plan }}$

Descriptive statistics were performed, reporting means and standard deviations for the menopausal status groups (pre-menopausal, peri-menopausal, and post-menopausal groups) on demographic variables, proposed moderators, and dependent variables. Analysis of variance (ANOVA) and chi-square analyses were conducted to compare the groups on all the demographic variables, with variables that were significantly different between groups 
considered as covariates for analyses. Correlations among study variables were also performed as part of descriptive statistics for this sample.

For the first aim related to comparing disordered eating and body image concerns across menopausal status groups, Multivariate Analysis of Variance (MANOVA) was used for the set of disordered eating dependent variables (broad eating pathology, bulimic symptoms, and dietary restraint) and Analysis of Variance (ANOVA) was used for the body image concerns dependent variable. In all cases, menopausal group status was the independent variable. Significant MANOVA findings were followed up with ANOVAs and Tukey's tests for pairwise comparisons; significant ANOVA findings were followed up with Tukey's tests for pairwise comparisons. Potential covariates considered were pharmacological interventions for menopause and demographic variables that were significantly different across menopausal group and related to dependent variables. When covariates were deemed necessary, initial analyses were Analysis of Covariance (ANCOVA) or Multivariate Analysis of Covariance (MANCOVA).

For the second aim related to testing potential moderators of the association between menopausal status and disordered eating and body image concerns, hierarchical multiple regression models were used. Step one contained the presence or absence of pharmacological interventions (hormone therapy, vaginal estrogen, or antidepressants) and demographic variables, as needed, as covariates. Step two contained our independent variable, menopausal status and a hypothesized moderator (e.g., attitudes toward aging). Given that menopausal status is a multicategorical variable, the three levels were dummy coded into two indicator variables: premenopausal women $($ coded $0=$ no, and $1=$ yes $)$, and post-menopausal women $(\operatorname{coded} 0=$ no, and $1=$ yes) in all regression models. Thus, peri-menopausal status was assigned as the reference category when both pre-menopausal and post-menopausal status were coded 0 . Step three 
contained our two-way interaction term between the independent variable and moderator (e.g., menopausal status $\mathrm{x}$ attitudes toward aging). We evaluated interaction models for all potential dependent variables (i.e., the disordered eating variables and body image concern). To minimize concerns related to multicollinearity, scores for both continuous moderators (attitudes toward aging and body comparison) were centered around their grand means. For all analyses, if an interaction effect was significant, we graphed and probed the nature of the interaction using the PROCESS macro for SPSS (Hayes, 2013). The PROCESS macro generates unstandardized regression output, including coefficient estimates of the focal predictor on the dependent variable, at three levels of the moderator set at low (one $S D$ below the mean), moderate (sample mean), and high (one $S D$ above the mean). Current analyses used PROCESS Model 1 to account for the multicategorical moderator, menopausal status (Hayes \& Montoya, 2017). All statistical analyses were conducted using IBM SPSS Statistics version 24.

\section{Results}

Across the total sample of middle-aged women, the mean broad eating pathology score was approximately $6.89(S D=6.27)$. The mean score for bulimic symptoms in the total sample was approximately $11.35(S D=4.38)$. The mean dietary restraint score was approximately 1.24 $(S D=1.23)$, and the mean score for body image concerns was approximately $2.06(S D=1.42)$.

Descriptive statistics of demographic variables for pre-, peri-, and post-menopausal women, along with results from chi-square analyses and ANOVAs with follow-up Tukey's tests, are presented in Table 1. Not surprisingly, age significantly differed by group with the postmenopausal women being significantly older than the peri-menopausal women, who were significantly older than the pre-menopausal women. Additionally, race significantly differed by menopausal group. A significantly higher percentage of women self-identified as white in the 
post-menopausal group, compared to the pre- and peri-menopausal groups; however, there were no differences related to race between the pre- and peri-menopausal groups. Groups did not significantly differ by Latina ethnicity, BMI, or level of education.

Correlations among demographic variables, menopause interventions, menopausal status, and the core study constructs are presented in Table 2 . In general, results indicate that age and level of education were inversely associated with body image concerns $(p s<.05)$, but not significantly related to disordered eating $(p s>.121)$. Additionally, BMI was positively associated with body image concerns $(p<.001)$, bulimic symptoms $(p<.001)$, and dietary restraint $(p=.027)$. However, race, ethnicity, interventions for menopause, and menopausal status were not significantly correlated with any of the measures of disordered eating or body image concerns $(p s>.130)$. Given that age was the only variable that both differed by menopausal group, and was significantly correlated with a dependent variable (body image concerns), the models involving body image concerns included age as a covariate. For models considering all other disordered eating outcomes, no covariates were included.

\section{Comparison of Menopausal Groups on Disordered Eating and Body Image Concerns}

For our first aim, comparing disordered eating and body image concerns across menopausal status groups, results indicated no significant group differences for both disordered eating behaviors and body image concerns across pre-menopausal, peri-menopausal, and postmenopausal women. In particular, the MANOVA involving the set of disordered eating behaviors was not significant: $F(6,502)=.03, p=.546$, Wilks' Lambda $=.125$, partial $\eta^{2}=.01$. Similarly, the ANCOVA (with age as a covariate) for body image concerns was not significant: $F(2,307)=.51, p=.599$, partial $\eta^{2}=.003$. Means and standard deviations for the disordered eating behaviors and body image concerns across menopausal groups are presented in Table 3. 


\section{$\underline{\text { Attitudes towards Aging Moderator Models }}$}

Disordered eating. Our second aim, focused on evaluating attitudes about aging and body comparison as potential moderators of the association between menopausal status and disordered eating and body image concerns, yielded mixed results (see Tables 4 and 5). We found a significant interaction between menopausal status and attitudes about aging on dietary restraint $(p=.005)$. Using the PROCESS macro for SPSS to directly test our hypothesis of a continuous variable (attitudes about aging) moderating the effects of a multicategorical independent variable (menopausal status) on a continuous dependent variable (e.g., dietary restraint) (Hayes, 2013), results suggest that among women who were low in negative attitudes about aging (those with scores 1 standard deviation below the mean), those who were perimenopausal reported greater dietary restraint than those who were either pre-menopausal $(p=$ .009 ) or post-menopausal $(p=.017)$, yet there were no significant differences between pre- and post-menopausal women $(p=.778$; see Figure 1$)$.

Another way to understand the nature of a significant interactions involves an examination of slopes to see, for example, for which menopausal status are differing levels of aging concerns associated with differing levels of outcomes. Simple slopes tests revealed that the relationship between aging concerns and dietary restraint among peri-menopausal women was not significantly different than zero $(p=.544)$. However, there were significant and positive relationships between aging concerns and dietary restraint among both pre-menopausal $(B=.30$, $p<.001)$ and post-menopausal women $(B=.31, p<.001)$.

Results revealed no significant interactions between menopausal status and attitudes about aging for either broad eating pathology or bulimic symptoms ( $p s>.108)$. 
Body image concerns. Controlling for age, we found a marginally significant interaction between menopausal status and attitudes about aging for body image concerns $(p=.054)$ (see Table 4). Probing the interaction according to our hypothesis and the PROCESS macro, it seems that among women who were low in negative attitudes about aging, those who were perimenopausal reported marginally more body image concerns compared to women who were premenopausal ( $p=.062$; see Figure 2). However, among those low in negative attitudes about aging, there were no significant differences between those who were peri-menopausal and postmenopausal $(p=.403)$, or pre-menopausal and post-menopausal $(p=.320)$.

Exploring the interaction via simple slope analyses, we can comment that results revealed positive and significant relationships between aging concerns and body image concerns among pre-menopausal $(B=.43, p<.001)$, peri-menopausal $(B=.21, p=.003)$, and post-menopausal women $(B=.37, p<.001)$. Thus, aging concerns was related to body image concerns for all menopausal status groups, although inspection of the betas suggests that this relationship is weakest in the peri-menopausal group.

\section{Body Comparison Moderator Models}

Disordered eating. Regarding models evaluating body comparison as a moderator, we found a significant interaction between menopausal status and body comparison on dietary restraint $(p=.021)$. Probing the interaction indicates that, among women who were high in body comparison (those who scored 1 standard deviation above the mean), post-menopausal women reported significantly more restraint compared to both peri-menopausal women $(p=.036)$ and pre-menopausal women $(p=.023)$, yet there were no significant differences between peri- and pre-menopausal women $(p=.86$; see Figure 3). 
Exploring the interaction via simple slope analyses, we can comment that results revealed a significant and positive relationship between body comparison and dietary restraint among premenopausal $(B=.06, p<.001)$, peri-menopausal $(B=.04, p=.013)$, and post-menopausal women $(B=.10, p<.001)$. Results revealed no significant interactions between menopausal status and body comparison for broad eating pathology or bulimic symptoms ( $p$ s > .175).

Body image concerns. Controlling for age, results revealed no significant interaction between menopausal status and body comparison for body image concerns $(p=.464)$.

\section{Discussion}

The goals of this study were twofold: (1) to compare disordered eating and body image concerns for women across varying levels of menopausal status (pre-, peri-, and postmenopausal), and (2) to identify which women might be most at risk for an association between menopausal status and disordered eating and body image concerns by evaluating attitudes towards aging and body comparison as potential moderators of this relationship.

In general, the current sample reported comparable levels of broad eating pathology (Johnson \& Bedford, 2004), bulimic symptoms (Mangweth-Matzek et al., 2013), and dietary restraint and body image concerns (Rø, Reas, \& Rosenvinge, 2012) compared to other community samples of middle-aged women. Women in the current study also reported comparable levels of broad eating pathology (Garner et al., 1982), bulimic symptoms (Schoemaker et al., 1994), and dietary restraint and body image concerns (Mond, Hay, Rodgers, \& Owen, 2006) compared to community samples of younger adult females as well. Thus, we are confident the current sample serves as an accurate representation of the disordered eating behaviors of the broader population of middle-aged women. 
Our first hypothesis, that peri-menopausal women would report more disordered eating and body image concerns compared to both the pre-menopausal and post-menopausal women was not supported by the data. In fact, there was no support for any group differences, which is inconsistent with prior research. Although there is little consistency about which stage of menopause is most at-risk, past studies have found significant group differences suggesting that post-menopausal women report greater dietary restraint and eating disinhibition compared to premenopausal women (Copeland et al., 2006; Drobnjak et al., 2014), and that peri-menopausal women have a greater prevalence of eating disorders and greater body shape and weight preoccupation compared to pre-menopausal women (Mangweth-Matzek et al., 2013). One potential explanation for this lack of consistency between the current study and prior research is that moderators may be important in determining when there are group differences across menopausal status.

Our second aim began to evaluate two potential moderators of the association between menopausal status and disordered eating and body image concerns, attitudes about aging and body comparison, yielding mixed results. Although we predicted that being in the transitional period of menopause (i.e., peri-menopause) would be most strongly related to body image concerns and disordered eating among those with high levels of negative attitudes about aging, results indicated that it is among women with low levels of negative attitudes about aging for which the peri-menopausal period was associated with greater dietary restraint compared to women in the pre-menopausal or post-menopausal period. Additionally, even though not statistically significant, the same pattern seemed to appear for women regarding body image concerns. Specifically, among women who were low in negative attitudes about aging, those in 
the peri-menopausal period indicated greater body image concerns compared to those in the premenopausal period.

Although they were not the focus of our hypotheses, results from simple slopes analyses suggest peri-menopausal women have a relatively consistent level of dietary restraint, regardless of aging concerns. It appears that dietary restraint among both peri- and post-menopausal women changes according to their aging concerns. Thus, being low in aging concerns may be a protective factor for both pre- and post-menopausal women, while having high negative attitudes about aging could be a risk factor for pre- and post-menopausal women. This is consistent with past research suggesting that middle-aged women who believe a thin body makes them look younger have excessive dieting concerns compared to those who don't believe being thin makes them appear younger (Gupta \& Schork, 1993).

Consistent with prior research (Baker, Girdler, et al., 2012; Baker \& Runfola, 2016), the PROCESS results testing our specific hypotheses regarding the relationship between perimenopausal status and outcomes in the context of attitudes about aging appear to indicate that there is something unique about the peri-menopausal period that puts women at risk for disordered eating and body image concerns compared to the pre-menopausal period. Given the significant and positive correlations between negative attitudes about aging and disordered eating and body image concerns in the current sample, it is possible that women who are high in negative attitudes about aging are already particularly resistant to the idea of their body and appearance changing as they age, and thus, have engaged in disordered eating and body image concerns prior to the menopause transition. Perhaps, women who are initially low in negative attitudes about aging are less prepared for or less aware of the degree to which the physiological changes associated with peri-menopause may affect their body or appearance, and thus this 
transitional period (and the associated physiological changes) may have larger effects on women's disordered eating and body image concerns compared to women in the other menopausal groups where changes either have not yet occurred or have occurred and stabilized.-

Regarding body comparison as a potential moderator, we found no significant interaction between menopausal status and body comparison for body image concerns and most disordered eating measures. However, significant results emerged for body comparison moderating the relationship between menopausal status and dietary restraint. Specifically, we found that among women with high levels of body comparison, being post-menopausal was associated with greater dietary restraint compared to those who were either pre- or peri-menopausal. This is in contrast to our hypothesis that peri-menopausal women in particular would have the most elevated levels of dietary restraint in the context of high body comparison.

Although they were not the focus of our hypotheses, results from simple slopes analyses suggest a similar pattern among body comparison models that appeared for negative attitudes about aging models. Specifically, the relationship between body comparison and dietary restraint was strongest among pre- and post-menopausal women, compared to peri-menopausal women. This suggests that being high in body comparison could be a risk factor for dietary restraint among pre- and post-menopausal women and being low in body comparison could be a protective factor against dietary restraint among pre- and post-menopausal women.

It is interesting that body comparison only moderated the relationship between menopausal status and dietary restraint and not the relationship with any other type of disordered eating or body image concerns. Researchers evaluating appearance comparison and eating disorder symptoms have compared two types of appearance comparison: upward comparison versus downward comparison (Lin \& Soby, 2016). Upward appearance comparison occurs when 
a woman compares herself to someone whom she perceives to be more attractive than her, and downward appearance comparison occurs when a woman compares herself to someone whom she perceives as less attractive than her (Festinger, 1954). Lin and Soby (2016) found that among young adult women, upward comparison was associated with more eating disorder symptoms including body dissatisfaction, drive for thinness, and dietary restraint, whereas downward comparison was associated with only drive for thinness and dietary restraint. Fitzsimmons-Craft (2017) found similar results among college women: downward comparison was linked to dietary restraint while upward comparison was linked to body dissatisfaction. To our knowledge, no data have evaluated upward versus downward body comparison among middle-aged women. However, these findings among younger women suggest the possibility that perhaps middle-aged women engage in more downward than upward comparison. If the middle-aged women in the current sample tended to compare their physical appearance to people they perceived as less attractive than them, then this could explain the significant moderation findings for dietary restraint but not body image concerns. Future studies should examine upward versus downward body comparison as separate constructs to better understand these factors among middle-aged women.

There are some strengths to be highlighted in the current study. This study is the first to examine potential risk factors for body image concerns and disordered eating behaviors among menopausal women. Additionally, the large sample let us consider menopausal status with more nuance (pre-, peri-, and post-menopause) than studies only comparing pre- and post-menopausal women.

However, there are several limitations to be noted as well. As the study design was an online, cross-sectional survey, we had to rely on self-report methods for assessing menopausal 
status. Given that the best objective method of determining menopausal status is through blood tests, it is possible that women unknowingly misidentified their status if they had not had the appropriate tests done by a physician recently. Further, the cross-sectional design of the study limits our ability to test developmental questions regarding the temporal nature of our variables including mediation models (e.g., does menopausal status exacerbate attitudes about aging and thus lead to restrictive dieting?). Another limitation is our lack of data regarding mental health or physical health history among the sample. For example, we do not know which women may have had a history of an eating disorder earlier in their life, so we cannot make any conclusions regarding these disordered eating behaviors and attitudes newly developing or being exacerbated during this mid-life period.

We believe these findings introduce several important future research directions. Prior data indicate that both attitudes about aging and attitudes towards menopause may differ according to culture. For example, Yun and Lachman (2006) found that, compared to Americans, Koreans reported overall higher levels of anxiety about aging and greater levels of fear of older people. Among a diverse American sample, Hispanic adults reported significantly greater anxiety about aging compared to non-Hispanic Whites, yet non-Hispanic Whites did not differ compared to African Americans (Yan, Silverstein, \& Wilber, 2011). Other data suggest that African Americans seemed to have more positive attitudes about menopause compared to nonHispanic Whites (Sommer et al., 1999). Given that aging concerns and attitudes towards menopause may vary according to one's race or culture, future studies should test these constructs in more diverse samples to determine if certain populations are more at-risk for developing body image concerns and disordered eating behaviors during menopause than others. 
Another direction for future studies would be to take a developmental approach to examining risk throughout a woman's life. Given that researchers have found a link between pubertal development and risk for disordered eating behaviors among adolescents (Baker, Thornton, Lichtenstein, \& Bulik, 2012), and given the analogous fluctuation of reproductive hormones seen during both puberty and menopause (Steiner, Dunn, \& Born, 2003), future studies should employ longitudinal methods to examine if a woman's experience with puberty and disordered eating is related to her experience with disordered eating during other points of hormonal changes in her life including during pregnancy and menopause. Future research could better understand if some women are more at risk for eating pathology during major hormonal life events such as puberty, pregnancy, and menopause by adopting a developmental perspective.

The finding that peri-menopausal women with low negative aging concerns and postmenopausal women high in body comparison appear to be most at risk for dietary restraint has important clinical implications as well. These data may help clinicians target those most at risk for disordered eating during the menopause transition as well as post-menopause. For example, evaluating clients' attitudes about aging, particularly when they enter the menopause transition, may serve as a marker for clinicians working with this population. Client's knowledge or psychoeducation about aging, which may inform their attitudes, should also be assessed and accurately bolstered.

In conclusion, the current study explored potential moderators (attitudes towards aging and body comparison) of the relationship between menopausal status and disordered eating behaviors and attitudes. Results suggest that for women low in negative attitudes about aging, the peri-menopausal period may be a particularly vulnerable time for dietary restraint compared to both the pre-menopausal and the post-menopausal stages. Additionally, for women high in body 
comparison, the post-menopausal period is more strongly associated with dietary restraint compared to both the pre-menopausal and peri-menopausal periods. 


\section{REFERENCES}

Ahern, A. L., Bennet, K. M., \& Hetherington, M. M. (2008). Internalization of the ultra-thin ideal: Positive implicit associations with underweight fashion models are associated with drive for thinness in young women. Eating Disorders, 16, 294-307. https://doi.org/doi: 10.1080-10640260802115852

Baker, J. H., Girdler, S. S., \& Bulik, C. M. (2012). The role of reproductive hormones in the development and maintenance of eating disorders. Expert Review of Obstetrics \& Gynecology, 7, 573-583. https://doi.org/10.1586/eog.12.54

Baker, J. H., \& Runfola, C. D. (2016). Eating disorders in midlife women: A perimenopausal eating disorder? Maturitas, 85, 112-116. https://doi.org/10.1016/j.maturitas.2015.12.017

Baker, J. H., Thornton, L. M., Lichtenstein, P., \& Bulik, C. M. (2012). Pubertal development predicts eating behaviors in adolescence. International Journal of Eating Disorders, 45, 819-826. https://doi.org/10.1002/eat.22022

Bardone-Cone, A. M., Balk, M., Lin, S. L., Fitzsimmons-Craft, E. E., \& Goodman, E. L. (2016). Female friendships and relations with disordered eating. Journal of Social and Clinical Psychology, 35, 781-805. https://doi.org/10.1521/jscp.2016.35.9.781

Bloch, A. (2002). Self-awareness during menopause. Maturitas, 41, 61-68. https://doi.org/10.1016/S0378-5122(01)00252-3

Chrisler, J. C., \& Ghiz, L. (1993). Body image issues of older women. Women \& Therapy, 14, 67-75. https://doi.org/10.1300/J015v14n01_07

Clausen, L., Rosenvinge, J. H., Friborg, O., \& Rokkedal, K. (2011). Validating the Eating Disorder Inventory-3 (EDI-3): A Comparison Between 561 Female Eating Disorders Patients and 878 Females from the General Population. Journal of Psychopathology and Behavioral Assessment, 33, 101-110. https://doi.org/10.1007/s10862-010-9207-4

Conboy, L., Domar, A., \& O’Connell, E. (2001). Women at mid-life: symptoms, attitudes, and choices, an internet based survey. Maturitas, 38, 129-136.

Copeland, A. L., Martin, P. D., Geiselman, P. J., Rash, C. J., \& Kendzor, D. E. (2006). Predictors of pretreatment attrition from smoking cessation among pre- and postmenopausal, weight-concerned women. Eating Behaviors, 7. https://doi.org/10.1016/j.eatbeh.2005.10.001

Cumella, E. J., \& Kally, Z. (2008). Profile of 50 women with midlife-onset eating disorders. Eating Disorders, 16. https://doi.org/10.1080/10640260802016670

Dakanalis, A., Carrà, G., Calogero, R., Fida, R., Clerici, M., Zanetti, M. A., \& Riva, G. (2015). The developmental effects of media-ideal internalization and self-objectification processes on adolescents' negative body-feelings, dietary restraint, and binge eating. 
European Child \& Adolescent Psychiatry, 24, 997-1010. https://doi.org/10.1007/s00787014-0649-1

Daly, J. (1995). Caught in the web: The social construction of menopause as disease. Journal of Reproductive and Infant Psychology, 13, 115-126. https://doi.org/10.1080/02646839508403241

Deeks, A. A., \& McCabe, M. P. (2001). Menopausal stage and age and perceptions of body image. Psychology \& Health, 16, 367-379. https://doi.org/10.1080/08870440108405513

Drobnjak, S., Atsiz, S., Ditzen, B., Tuschen-Caffier, B., \& Ehlert, U. (2014). Restrained eating and self-esteem in premenopausal and postmenopausal women. Journal of Eating Disorders, 2, 1-10. https://doi.org/10.1186/s40337-014-0023-1

Fairburn, C. G., \& Beglin, S. J. (1994). Assessment of eating disorders: Interview or self-report questionnaire? International Journal of Eating Disorders, 16, 363-370. Retrieved from http://onlinelibrary.wiley.com/journal/10.1002/(ISSN)1098-108X

Festinger, L. (1954). A theory of social comparison processes. Human Relations, 7, 117-140. https://doi.org/10.1177/001872675400700202

Fitzsimmons-Craft, E. E. (2017). Eating disorder-related social comparison in college women's everyday lives. International Journal of Eating Disorders, 50, 893-905. https://doi.org/10.1002/eat.22725

Fitzsimmons-Craft, E. E., Bardone-Cone, A. M., \& Harney, M. B. (2012). Development and validation of the Body, Eating, and Exercise Comparison Orientation Measure (BEECOM) among college women. Body Image, 9, 476-487. https://doi.org/10.1016/j.bodyim.2012.07.007

Flint, M., \& Samil, R. S. (1990). Cultural and subcultural meanings of the menopause. In M. Flint, F. Kronenberg, W. Utian, M. Flint (Ed), F. Kronenberg (Ed), \& W. Utian (Ed) (Eds.), Multidisciplinary Perspectives on Menopause (Vol. 592, pp. 134-148). New York, NY, US: New York Academy of Sciences. Retrieved from https://auth.lib.unc.edu/ezproxy_auth.php?url=http://search.ebscohost.com/login.aspx?dir ect=true $\& \mathrm{db}=$ psyh $\& A N=1990-98393-007 \&$ site $=$ ehost-live $\&$ scope $=$ site

Forbes, G. B., Adams-Curtis, L., Jobe, R. L., White, K. B., Revak, J., Zivcic-Becirevic, I., \& Pokrajac-Bulian, A. (2005). Body dissatisfaction in college women and their mothers: Cohort effects, developmental effects, and the influences of body size, sexism, and the thin body ideal. Sex Roles, 53, 281-298. https://doi.org/10.1007/s11199-005-5686-2

Fu, S.-Y., Anderson, D., \& Courtney, M. (2003). Cross-cultural menopausal experience: Comparison of Australian and Taiwanese women. Nursing \& Health Sciences, 5, 77-84. https://doi.org/10.1046/j.1442-2018.2003.00139.x

Gagne, D. A., Von Holle, A., Brownley, K. A., Runfola, C. D., Hofmeier, S., Branch, K. E., \& Bulik, C. M. (2012). Eating disorder symptoms and weight and shape concerns in a large 
web-based convenience sample of women ages 50 and above: results of the gender and body image (GABI) study. International Journal of Eating Disorders, 45. https://doi.org/10.1002/eat.22030

Garner, D. M., \& Garfinkel, P. E. (1979). The Eating Attitudes Test: An index of the symptoms of anorexia nervosa. Psychological Medicine, 9, 273-279. https://doi.org/10.1017/S0033291700030762

Garner, D. M., Olmsted, M. P., Bohr, Y., \& Garfinkel, P. E. (1982). The Eating Attitudes Test: Psychometric features and clinical correlates. Psychological Medicine, 12, 871-878. https://doi.org/10.1017/S0033291700049163

Garner, D. M., Olmsted, M. P., \& Polivy, J. (1983). Development and validation of a multidimensional eating disorder inventory for anorexia nervosa and bulimia. International Journal of Eating Disorders, 2, 15-34. https://doi.org/10.1002/1098108X(198321)2:2<15::AID-EAT2260020203>3.0.CO;2-6

Grabe, S., Ward, L. M., \& Hyde, J. S. (2008). The role of the media in body image concerns among women: A meta-analysis of experimental and correlational studies. Psychological Bulletin, 134, 460-476. https://doi.org/10.1037/0033-2909.134.3.460

Grippo, K. P., \& Hill, M. S. (2008). Self-objectification, habitual body monitoring, and body dissatisfaction in older European American women: Exploring age and feminism as moderators. Body Image, 5, 173-182. https://doi.org/10.1016/j.bodyim.2007.11.003

Groesz, L. M., Levine, M. P., \& Murnen, S. K. (2002). The effect of experimental presentation of thin media images on body satisfaction: A meta-analytic review. International Journal of Eating Disorders, 31, 1-16. https://doi.org/10.1002/eat.10005

Guđnadóttir, U., \& Garđarsdóttir, R. B. (2014). The influence of materialism and ideal body internalization on body-dissatisfaction and body-shaping behaviors of young men and women: Support for the Consumer Culture Impact Model. Scandinavian Journal of Psychology, 55, 151-159. https://doi.org/10.1111/sjop.12101

Gupta, M. A. (1995). Concerns about aging and a drive for thinness: A factor in the biopsychosocial model of eating disorders? International Journal of Eating Disorders, 18, 351-357. https://doi.org/10.1002/1098-108X(199512)18:4<351::AIDEAT2260180408>3.0.CO;2-L

Gupta, M. A., \& Schork, N. J. (1993). Aging-related concerns and body image: Possible future implications for eating disorders. International Journal of Eating Disorders, 14, 481486. https://doi.org/10.1002/1098-108X(199312)14:4<481::AIDEAT2260140411>3.0.CO;2-G

Halliwell, E., \& Dittmar, H. (2003). A Qualitative Investigation of Women's and Men's Body Image Concerns and Their Attitudes Toward Aging. Sex Roles, 49, 675-684. https://doi.org/10.1023/B:SERS.0000003137.71080.97 
Hayes, A. F. (2013). Introduction to mediation, moderation, and conditional process analysis: A regression-based approach. New York, NY, US: Guilford Press. Retrieved from https://auth.lib.unc.edu/ezproxy_auth.php?url=http://search.ebscohost.com/login.aspx?dir ect $=$ true $\& \mathrm{db}=$ psyh $\& \mathrm{AN}=2013-21121-000 \&$ site $=$ ehost-live $\&$ scope $=$ site

Hayes, A. F., \& Montoya, A. K. (2017). A Tutorial on Testing, Visualizing, and Probing an Interaction Involving a Multicategorical Variable in Linear Regression Analysis. Communication Methods and Measures, 11, 1-30. https://doi.org/10.1080/19312458.2016.1271116

Henderson, V. W., \& Sherwin, B. B. (2007). Surgical versus natural menopause: cognitive issues. Menopause (New York, N.Y.), 14, 572-579. https://doi.org/10.1097/gme.0b013e31803df49c

Ho, S. C., Wu, S., Chan, S. G., \& Sham, A. (2010). Menopausal transition and changes of body composition: A prospective study in Chinese perimenopausal women. International Journal of Obesity, 34, 1265-1274. https://doi.org/10.1038/ijo.2010.33

Im, E.-O., Liu, Y., Dormire, S., \& Chee, W. (2008). Menopausal symptom experience: An online forum study. Journal of Advanced Nursing, 62, 541-550. https://doi.org/10.1111/j.13652648.2008.04624.x

Johnson, C. S., \& Bedford, J. (2004). Eating attitudes across age and gender groups: A Canadian study. Eating and Weight Disorders, 9, 16-23. https://doi.org/10.1007/BF03325040

Katz, W. A. (2005). An examination of the relationship between physical appearance, personality, internalization of sociocultural norms, and anxiety about aging among middle-aged White women. ProQuest Information \& Learning, US. Retrieved from https://auth.lib.unc.edu/ezproxy_auth.php?url=http://search.ebscohost.com/login.aspx?dir ect $=$ true $\& d b=$ psyh $\& A N=2005-99022-100 \&$ site $=$ ehost-live $\&$ scope $=$ site

Kaufert, P., Lock, M., McKinlay, S., Beyenne, Y., Coope, J., Davis, D., ... Holte, A. (1986). Menopause research: The Korpilampi workshop. Social Science \& Medicine, 22, 12851289. https://doi.org/10.1016/0277-9536(86)90196-6

Keery, H., van den Berg, P., \& Thompson, J. K. (2004). An evaluation of the Tripartite Influence Model of body dissatisfaction and eating disturbance with adolescent girls. Body Image, 1, 237-251. https://doi.org/10.1016/j.bodyim.2004.03.001

King, M. B. (1991). The natural history of eating pathology in attenders to primary medical care. International Journal of Eating Disorders, 10, 379-387. Retrieved from http://onlinelibrary.wiley.com/journal/10.1002/(ISSN)1098-108X

Koch, P. B., Mansfield, P. K., Thurau, D., \& Carey, M. (2005). "Feeling Frumpy": the relationship between body image and sexual response changes in midlife women. The Journal of Sex Research, 42. https://doi.org/10.1080/00224490509552276 
Lewis, D. M., \& Cachelin, F. M. (2001). Body image, body dissatisfaction, and eating attitudes in midlife and elderly women. Eating Disorders: The Journal of Treatment \& Prevention, 9, 29-39. https://doi.org/10.1080/106402601300187713

Lin, L., \& Soby, M. (2016). Appearance comparisons styles and eating disordered symptoms in women. Eating Behaviors, 23, 7-12. https://doi.org/10.1016/j.eatbeh.2016.06.006

Luce, K. H., \& Crowther, J. H. (1999). The reliability of the Eating Disorder Examination-SelfReport Questionnaire Version (EDE-Q). International Journal of Eating Disorders, 25, 349-351. https://doi.org/10.1002/(SICI)1098-108X(199904)25:3<349::AIDEAT15>3.0.CO;2-M

Mangweth-Matzek, B., Hoek, H. W., \& Pope, H. G. J. (2014). Pathological eating and body dissatisfaction in middle-aged and older women. Current Opinion in Psychiatry, 27, 431435. https://doi.org/10.1097/YCO.0000000000000102

Mangweth-Matzek, B., Hoek, H. W., Rupp, C. I., Kemmler, G., Pope, H. G., \& Kinzl, J. (2013). The menopausal transition-a possible window of vulnerability for eating pathology. International Journal of Eating Disorders, 46. https://doi.org/10.1002/eat.22157

Mangweth-Matzek, B., Hoek, H. W., Rupp, C. I., Lackner-Seifert, K., Frey, N., Whitworth, A. B., ... Kinzl, J. (2014). Prevalence of eating disorders in middle-aged women. International Journal of Eating Disorders, 47, 320-324. https://doi.org/10.1002/eat.22232

Mangweth-Matzek, B., Rupp, C. I., Hausmann, A., Assmayr, K., Mariacher, E., Kemmler, G., ... Biebl, W. (2006). Never too old for eating disorders or body dissatisfaction: A community study of elderly women. International Journal of Eating Disorders, 39. https://doi.org/10.1002/eat.20327

Matz, P. E., Foster, G. D., Faith, M. S., \& Wadden, T. A. (2002). Correlates of body image dissatisfaction among overweight women seeking weight loss. Journal of Consulting and Clinical Psychology, 70, 1040-1044. https://doi.org/10.1037/0022-006X.70.4.1040

McKinley, N. M., \& Lyon, L. A. (2008). Menopausal attitudes, objectified body consciousness, aging anxiety, and body esteem: European American women's body experiences in midlife. Body Image, 5. https://doi.org/10.1016/j.bodyim.2008.07.001

Mcknight, K. K., Wellons, M. F., Sites, C. K., Roth, D. L., Szychowski, J. M., Halanych, J. H., ... Safford, M. M. (2011). Racial and Regional Differences in Age at Menopause in the United States: Findings from the Reasons for Geographic and Racial Differences in Stroke (REGARDS) Study. American Journal of Obstetrics and Gynecology, 205, 353.e1-353.e8. https://doi.org/10.1016/j.ajog.2011.05.014

McLaren, L., Hardy, R., \& Kuh, D. (2003). Women's body satisfaction at midlife and lifetime body size: A prospective study. Health Psychology, 22, 370-377. https://doi.org/10.1037/0278-6133.22.4.370 
McLean, S. A., Paxton, S. J., \& Wertheim, E. H. (2010). Factors associated with body dissatisfaction and disordered eating in women in midlife. International Journal of Eating Disorders, 43. https://doi.org/10.1002/eat.20737

Midlarsky, E., \& Nitzburg, G. (2008). Eating disorders in middle-aged women. Journal of General Psychology, 135, 393-407. https://doi.org/10.3200/GENP.135.4.393-408

Mond, J., Hay, P. J., Rodgers, B., \& Owen, C. (2006). Eating Disorder Examination Questionnaire (EDE-Q): norms for young adult women. Behav Res Ther, 44. https://doi.org/10.1016/j.brat.2004.12.003

Papalia, D. E. (Ed.). (2007). Adult development and aging (3rd ed.). New York: McGraw-Hill.

Park, J., \& Beaudet, M. P. (2007). Eating attitudes and their correlates among Canadian women concerned about their weight. European Eating Disorders Review, 15, 311-320. https://doi.org/10.1002/erv.741

Peterson, C. B., Crosby, R. D., Wonderlich, S. A., Joiner, T., Crow, S. J., Mitchell, J. E., ... le Grange, D. (2007). Psychometric properties of the eating disorder examinationquestionnaire: Factor structure and internal consistency. International Journal of Eating Disorders, 40, 386-389. https://doi.org/10.1002/eat.20373

Porter, M., Penney, G. C., Russell, D., Russell, E., \& Templeton, A. (1996). A population based survey of women's experience of the menopause. BJOG: An International Journal of Obstetrics \& Gynaecology, 103, 1025-1028. https://doi.org/10.1111/j.14710528.1996.tb09555.x

Procopio, C. A., Holm-Denoma, J. M., Gordon, K. H., \& Joiner, T. E. J. (2006). Two-ThreeYear Stability and Interrelations of Bulimotypic Indicators and Depressive and Anxious Symptoms in Middle-Aged Women. International Journal of Eating Disorders, 39, 312319. https://doi.org/10.1002/eat.20242

Qualtrics. (2005). Provo, Utah: Qualtrics. Retrieved from http://www.qualtrics.com

Rø, Ø., Reas, D. L., \& Rosenvinge, J. (2012). The impact of age and BMI on Eating Disorder Examination Questionnaire (EDE-Q) scores in a community sample. Eating Behaviors, 13, 158-161. https://doi.org/10.1016/j.eatbeh.2011.12.001

Saucier, M. G. (2004). Midlife and Beyond: Issues for Aging Women. Journal of Counseling \& Development, 82, 420-425. https://doi.org/10.1002/j.1556-6678.2004.tb00329.x

Schaefer, L. M., \& Thompson, J. K. (2014). The development and validation of the Physical Appearance Comparison Scale-Revised (PACS-R). Eating Behaviors, 15, 209-217. https://doi.org/10.1016/j.eatbeh.2014.01.001

Schoemaker, C., van Strien, T., \& van der Staak, C. (1994). Validation of the eating disorders inventory in a nonclinical population using transformed and untransformed responses. 
International Journal of Eating Disorders, 15, 387-393.

https://doi.org/10.1002/eat.2260150409

Slater, A., \& Tiggemann, M. (2002). A test of Objectification Theory in adolescent girls. Sex Roles, 46, 343-349. https://doi.org/10.1023/A:1020232714705

Slevec, J. H., \& Tiggemann, M. (2011). Predictors of body dissatisfaction and disordered eating in middle-aged women. Clinical Psychology Review, 31. https://doi.org/10.1016/j.cpr.2010.12.002

Sommer, B., Avis, N., Meyer, P., Ory, M., Madden, T., Kagawa-Singer, M., ... Adler, S. (1999). Attitudes toward menopause and aging across ethnic/racial groups. Psychosomatic Medicine, 61, 868-875. https://doi.org/10.1097/00006842-199911000-00023

Steiner, M., Dunn, E., \& Born, L. (2003). Hormones and mood: from menarche to menopause and beyond. Journal of Affective Disorders, 74, 67-83. https://doi.org/10.1016/S01650327(02)00432-9

Stunkard, A. J., \& Costello Allison, K. (2003). Two forms of disordered eating in obesity: binge eating and night eating. International Journal of Obesity, 27, 1-12. https://doi.org/10.1038/sj.ijo.0802186

Tiggemann, M., \& Lynch, J. E. (2001). Body image across the life span in adult women: the role of self-objectification. Developmental Psychology, 37, 243-253.

Tiggemann, M., \& Slater, A. (2015). The role of self-objectification in the mental health of early adolescent girls: Predictors and consequences. Journal of Pediatric Psychology, 40, 704711. https://doi.org/10.1093/jpepsy/jsv021

Tunaley, J. R., Walsh, S., \& Nicolson, P. (1999). 'I'm not bad for my age': the meaning of body size and eating in the lives of older women. Ageing Society, 19. https://doi.org/10.1017/S0144686X99007515

Utz, R. L. (2011). Like mother, (not) like daughter: The social construction of menopause and aging. Journal of Aging Studies, 25, 143-154. https://doi.org/10.1016/j.jaging.2010.08.019

van den Berg, P., Paxton, S. J., Keery, H., Wall, M., Guo, J., \& Neumark-Sztainer, D. (2007). Body dissatisfaction and body comparison with media images in males and females. Body Image, 4, 257-268. https://doi.org/10.1016/j.bodyim.2007.04.003

Voda, A., Christy, N., \& Morgan, J. (1991). Body composition changes in menopausal women. Women \& Therapy, 11, 71-96. https://doi.org/10.1300-J015V11N02_07

Wing, R. R., Matthews, K. A., Kuller, L. H., Meilahn, E. N., \& Plantinga, P. L. (1991). Weight gain at the time of menopause. Archives of Internal Medicine, 151. https://doi.org/10.1001/archinte.1991.00400010111016 
Wiseman, C. V., Sunday, S. R., Klapper, F., Harris, W. A., \& Halmi, K. A. (2001). Changing patterns of hospitalization in eating disorder patients. International Journal of Eating Disorders, 30, 69-74. https://doi.org/10.1002/eat.1055

World Health Organization. (1996). WHO Technical Report Series 866: Research on the menopause in the 1990s. Geneva, Switzerland: World Health Organization.

Yan, T., Silverstein, M., \& Wilber, K. H. (2011). Does race/ethnicity affect aging anxiety in American baby boomers? Research on Aging, 33, 361-378. https://doi.org/10.1177/0164027511403009

Yun, R. J., \& Lachman, M. E. (2006). Perceptions of aging in two cultures: Korean and American views on old age. Journal of Cross-Cultural Gerontology, 21, 55-70. https://doi.org/10.1007/s10823-006-9018-y 
Table 1

Descriptive Statistics and Group Comparisons on Demographic Variables

\begin{tabular}{|c|c|c|c|c|c|c|}
\hline & $\begin{array}{c}\text { Pre-Menopause } \\
\qquad(n=104)\end{array}$ & $\begin{array}{l}\text { Peri-Menopause } \\
\qquad(n=97)\end{array}$ & $\begin{array}{c}\text { Post- } \\
\text { Menopause } \\
(n=109)\end{array}$ & $\begin{array}{c}\text { ANOVA } \\
\text { (omnibus } F, p \text { - } \\
\text { value, partial } \eta^{2} \text { ) }\end{array}$ & $\begin{array}{c}\text { Chi-Square }\left(X^{2},\right. \\
p \text {-value })\end{array}$ & $\begin{array}{c}\text { Pairwise } \\
\text { comparisons } \\
\text { based on } \\
\text { Tukey's tests }\end{array}$ \\
\hline Age (years) & $46.66(3.45)$ & $49.53(3.17)$ & $54.01(3.60)$ & $\begin{array}{l}F(2,307)= \\
125.21, p<.001 \\
\text { partial } \eta^{2}=.45\end{array}$ & & $\begin{array}{l}\text { Post > Peri, Pre; } \\
\text { Peri > Pre }\end{array}$ \\
\hline $\begin{array}{l}\text { Race (\% } \\
\text { identifying } \\
\text { as white) }\end{array}$ & $69.2 \%$ & $79.4 \%$ & $91.7 \%$ & & $\begin{array}{l}X^{2}(2, \mathrm{~N}=310) \\
=17.14 \\
p<.001\end{array}$ & -- \\
\hline $\begin{array}{l}\text { Ethnicity (\% } \\
\text { identifying } \\
\text { as Latina) }\end{array}$ & $6.7 \%$ & $5.2 \%$ & $3.7 \%$ & & $\begin{array}{l}X^{2}(2, \mathrm{~N}=310) \\
=1.02 \\
p=.620\end{array}$ & -- \\
\hline $\begin{array}{l}\text { Highest } \\
\text { level of } \\
\text { education } \\
\text { (years) }\end{array}$ & $15.88(2.39)$ & $16.33(2.12)$ & $16.32(2.28)$ & $\begin{array}{l}F(2,307)=1.30 \\
p=.274 \\
\text { partial } \eta^{2}=.01\end{array}$ & & -- \\
\hline $\begin{array}{l}\text { Body mass } \\
\text { index } \\
\left(\mathrm{kg} / \mathrm{m}^{2}\right)\end{array}$ & $25.75(5.99)$ & $25.84(6.21)$ & $25.54(5.51)$ & $\begin{array}{l}F(2,304)=0.07 \\
p=.934 \\
\text { partial } \eta^{2}=.0004\end{array}$ & & -- \\
\hline
\end{tabular}


Note. Descriptive statistics are presented as means (standard deviations) or percentages. Highest level of education is presented in years $(12=$ high school graduation, $16=4$ year college, $21=\mathrm{PhD}$ or MD). For all continuous constructs, higher scores reflect greater levels of the constructs. Pairwise comparisons listed were significant at least at $p<.05$. 
Table 2

Correlations among Demographic Characteristics, Menopause Interventions, Menopausal Status, Attitudes about Aging, Body Comparison, Disordered Eating, and Body Image Concerns

\begin{tabular}{|c|c|c|c|c|c|c|c|c|c|c|c|c|c|}
\hline Variable & 1 & 2 & 3 & 4 & 5 & 6 & 7 & 8 & 9 & 10 & 11 & 12 & 13 \\
\hline 1. Age & - & & & & & & & & & & & & \\
\hline 2. Race & $.21 * * *$ & - & & & & & & & & & & & \\
\hline 3. Ethnicity & .02 & .07 & - & & & & & & & & & & \\
\hline 4. Level of education & $.17 * *$ & -.001 & .06 & - & & & & & & & & & \\
\hline 5. Body mass index & -.09 & -.11 & -.01 & $-.15 * *$ & - & & & & & & & & \\
\hline $\begin{array}{l}\text { 6. Menopause } \\
\text { interventions }\end{array}$ & $.21 * * *$ & $.19 * *$ & -.02 & .03 & -.06 & - & & & & & & & \\
\hline 7. Menopausal status & $.67 * * *$ & $.24 * * *$ & .06 & .08 & -.02 & $.30 * * *$ & - & & & & & & \\
\hline $\begin{array}{l}\text { 8. Attitudes about } \\
\text { aging }\end{array}$ & -.07 & .09 & .05 & .003 & .03 & .05 & -.03 & - & & & & & \\
\hline 9. Body comparison & -.05 & $.25 * * *$ & $.14^{*}$ & .03 & .07 & .04 & -.04 & $.56 * * *$ & - & & & & \\
\hline $\begin{array}{l}\text { 10. Broad eating } \\
\text { pathology }\end{array}$ & -.07 & -.09 & -.02 & -.08 & .07 & .003 & -.05 & $.31 * * *$ & $.29 * * *$ & - & & & \\
\hline 11. Bulimic symptoms & -.03 & -.001 & .02 & -.07 & $.34 * * *$ & -.01 & -.03 & $.25 * * *$ & $.41 * * *$ & $.34 * * *$ & - & & \\
\hline 12. Dietary restraint & -.004 & .06 & .02 & -.10 & $.14 *$ & .03 & .02 & $.38 * * *$ & $.41 * * *$ & $.56 * * *$ & $.32 * * *$ & - & \\
\hline $\begin{array}{l}\text { 13. Body image } \\
\text { concerns }\end{array}$ & $-.11 *$ & .01 & -.001 & $-.18 * *$ & $.49 * * *$ & -.03 & -.04 & $.48 * * *$ & $.55 * * *$ & $.43 * * *$ & $.54 * * *$ & $.51 * * *$ & - \\
\hline
\end{tabular}

Note. Race is coded $1=$ white and $0=$ other races. Ethnicity is coded $1=$ Hispanic or Latina and $0=$ non-Hispanic or Latina. Level of education is presented in years (e.g., $12=$ high school graduation, $16=4$ year college, $21=\mathrm{PhD}$ or MD). Menopause interventions include antidepressants, hormone therapy, or vaginal estrogen (coded 1 = any use of antidepressants, hormone therapy, or vaginal 
estrogen for menopause and $0=$ none of these interventions). Menopausal status is coded so that $0=$ pre-menopause, $1=$ perimenopause, and 2 = post-menopause. Attitudes towards aging assesses negative aging concerns related to physical appearance. Body comparison is measured by the Body Comparison Orientation subscale of the Body, Eating, and Exercise Comparison Orientation Measure. Broad eating pathology is measured by the Eating Attitudes Test-26. Bulimic symptoms are measured by the Bulimia subscale of the Eating Disorder Inventory. Dietary restraint and body image concerns are measured by the Eating Disorder Examination-Questionnaire. For all continuous constructs, higher scores indicate greater levels of the constructs. $* * * p<.001$. $* * p<$ $.01 . * p<.05$. 
Table 3

Descriptive Statistics of Outcome Variables

\begin{tabular}{|c|c|c|c|c|c|}
\hline & $\begin{array}{c}\text { Pre- } \\
\text { Menopause } \\
(n=104)\end{array}$ & $\begin{array}{c}\text { Peri- } \\
\text { Menopause } \\
(n=97)\end{array}$ & $\begin{array}{c}\text { Post- } \\
\text { Menopause } \\
(n=109)\end{array}$ & $\begin{array}{c}\text { MANOVA } \\
\text { (omnibus } F, p- \\
\text { value, partial } \\
\eta^{2} \text { ) }\end{array}$ & $\begin{array}{c}\text { ANCOVA } \\
\text { (omnibus } F, p \\
\text { value, partial } \\
\left.\eta^{2}\right)\end{array}$ \\
\hline $\begin{array}{l}\text { Broad eating } \\
\text { pathology }\end{array}$ & $6.95(6.08)$ & $7.51(6.58)$ & $6.29(6.17)$ & $\begin{array}{l}F(6,504)=.83 \\
p=.546 \\
\text { partial } \eta^{2}=.01\end{array}$ & \\
\hline $\begin{array}{l}\text { Bulimic } \\
\text { symptoms }\end{array}$ & $11.19(4.62)$ & $12.05(4.88)$ & $10.89(3.55)$ & $\begin{array}{l}F(6,504)=.83 \\
p=.546 \\
\text { partial } \eta^{2}=.01\end{array}$ & \\
\hline $\begin{array}{l}\text { Dietary } \\
\text { restraint }\end{array}$ & $1.16(1.13)$ & $1.35(1.31)$ & $1.22(1.27)$ & $\begin{array}{l}F(6,504)=.83 \\
p=.546 \\
\text { partial } \eta^{2}=.01\end{array}$ & \\
\hline $\begin{array}{l}\text { Body image } \\
\text { concerns }\end{array}$ & $2.09(1.51)$ & $2.17(1.44)$ & $1.95(1.33)$ & & $\begin{array}{l}F(2,306)=.51, \\
p=.599, \text { partial } \\
\eta^{2}=.003\end{array}$ \\
\hline
\end{tabular}

Note. Descriptive statistics are presented as means (standard deviations). To compare body image concerns across menopausal groups, ANCOVA was used controlling for age. Broad eating pathology is measured by the Eating Attitudes Test-26 (possible range; 0-78). Bulimic symptoms are measured by the Bulimia subscale of the Eating Disorder Inventory (possible range: 7-42). Dietary restraint is measured by the Eating Disorder Examination-Questionnaire (possible range: 0-6). Body image concerns is calculated from a combined score of the Weight Concerns and Shape Concerns subscales of the Eating Disorder Examination-Questionnaire (possible range: 06). For all constructs, higher scores reflect greater levels of the constructs. 
Table 4

Hierarchical Regression Analyses of the Interactions Between Menopausal Status and Attitudes about Aging on Women's Disordered Eating and Body Image Concerns

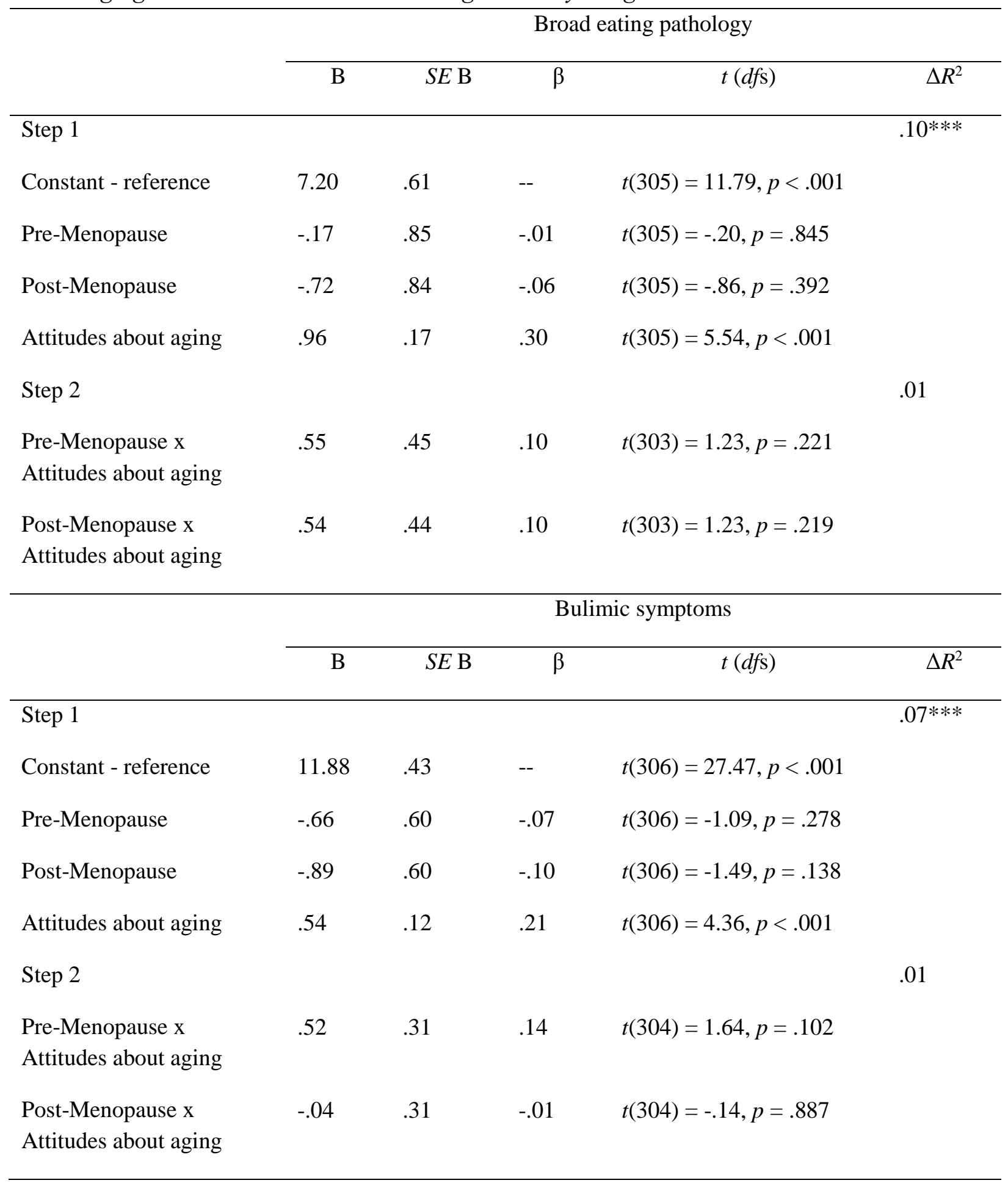




\begin{tabular}{lllll}
\hline \multicolumn{5}{c}{ Dietary restraint } \\
\hline $\mathrm{B}$ & $S E \mathrm{~B}$ & $\beta$ & $t(d f \mathrm{~s})$ & $\Delta R^{2}$
\end{tabular}

\begin{tabular}{|c|c|c|c|c|c|}
\hline Step 1 & & & & & $.15^{* * *}$ \\
\hline Constant - reference & 1.31 & .13 & -- & $t(254)=10.47, p<.001$ & \\
\hline Pre-Menopause & -.12 & .18 & -.05 & $t(254)=-.70, p=.482$ & \\
\hline Post-Menopause & -.05 & .18 & -.02 & $t(254)=-.30, p=.768$ & \\
\hline Attitudes about aging & .24 & .04 & .38 & $t(254)=6.46, p<.001$ & \\
\hline Step 2 & & & & & $.04 * *$ \\
\hline $\begin{array}{l}\text { Pre-Menopause } \mathrm{x} \\
\text { Attitudes about aging }\end{array}$ & .26 & .09 & .26 & $t(252)=2.89, p=.004$ & \\
\hline $\begin{array}{l}\text { Post-Menopause } \mathrm{x} \\
\text { Attitudes about aging }\end{array}$ & .27 & .09 & .26 & $t(252)=2.92, p=.004$ & \\
\hline
\end{tabular}

\begin{tabular}{|c|c|c|c|c|c|}
\hline & \multicolumn{5}{|c|}{ Body image concerns } \\
\hline & B & $S E \mathrm{~B}$ & $\beta$ & $t(d f \mathrm{~s})$ & $\Delta R^{2}$ \\
\hline Step 1 & & & & & $.01 *$ \\
\hline Age & -.04 & -.02 & -.11 & $t(308)=-2.02, p=.044$ & \\
\hline Step 2 & & & & & $.23 * * *$ \\
\hline Constant - reference & 3.80 & 1.04 & -- & $t(305)=3.75, p<.001$ & \\
\hline Pre-Menopause & -.03 & .19 & -.01 & $t(305)=-0.18, p=.855$ & \\
\hline Post-Menopause & .12 & .20 & .04 & $t(305)=0.62, p=.539$ & \\
\hline Attitudes about aging & .35 & .04 & .48 & $t(305)=9.51, p<.001$ & \\
\hline Step 3 & & & & & $.02 \dagger$ \\
\hline $\begin{array}{l}\text { Pre-Menopause } \mathrm{x} \\
\text { Attitudes about aging }\end{array}$ & .22 & .09 & .18 & $t(303)=2.38, p=.018$ & \\
\hline $\begin{array}{l}\text { Post-Menopause } \mathrm{x} \\
\text { Attitudes about aging }\end{array}$ & .16 & .09 & .14 & $t(303)=1.76, \mathrm{p}=.079$ & \\
\hline
\end{tabular}

Note. The multicategorical moderator, menopausal status, was dummy coded into premenopause and post-menopause, with peri-menopause as the reference category (designated Constant in the table above). Attitudes towards aging assesses negative aging concerns related to 
physical appearance. Broad eating pathology is measured by the Eating Attitudes Test- 26 . Bulimic symptoms are measured by the Bulimia subscale of the Eating Disorder Inventory. Dietary restraint is measured by the Eating Disorder Examination-Questionnaire. Body image concerns is calculated from a combined score of the Weight Concerns and Shape Concerns subscales of the Eating Disorder Examination-Questionnaire. For all continuous constructs, higher scores reflect greater levels of the constructs. ${ }^{* * *} p<.001 .{ }^{* *} p<.01 .{ }^{*} p<.05 . \dagger p<.06$. 
Table 5

Hierarchical Regression Analyses of the Interactions Between Menopausal Status and Body Comparison on Women's Disordered Eating and Body Image Concerns

\begin{tabular}{|c|c|c|c|c|c|}
\hline & \multicolumn{5}{|c|}{ Broad eating pathology } \\
\hline & $\mathrm{B}$ & $S E \mathrm{~B}$ & $\beta$ & $t(d f \mathrm{~s})$ & $\Delta R^{2}$ \\
\hline Step 1 & & & & & $.09 * * *$ \\
\hline Constant - reference & 7.14 & .62 & -- & $t(305)=11.60, p<.001$ & \\
\hline Pre-Menopause & -.11 & .85 & -.01 & $t(305)=-.13, p=.894$ & \\
\hline Post-Menopause & -.62 & .85 & -.05 & $t(305)=-.73, p=.464$ & \\
\hline Body comparison & .23 & .01 & .29 & $t(305)=5.21, p<.001$ & \\
\hline Step 2 & & & & & .01 \\
\hline $\begin{array}{l}\text { Pre-Menopause x Body } \\
\text { comparison }\end{array}$ & -.13 & .11 & -.10 & $t(303)=-1.23, p=.219$ & \\
\hline \multirow{3}{*}{$\begin{array}{l}\text { Post-Menopause x Body } \\
\text { comparison }\end{array}$} & -.05 & .11 & -.04 & $t(303)=-.49, p=.627$ & \\
\hline & \multicolumn{5}{|c|}{ Bulimic symptoms } \\
\hline & $\mathrm{B}$ & $S E \mathrm{~B}$ & $\beta$ & $t(d f \mathrm{~s})$ & $\Delta R^{2}$ \\
\hline Step 1 & & & & & $.18 * * *$ \\
\hline Constant - reference & 11.69 & .41 & -- & $t(306)=28.65, p<.001$ & \\
\hline Pre-Menopause & -.44 & .57 & -.05 & $t(306)=-.77, p=.443$ & \\
\hline Post-Menopause & -.54 & .56 & -.06 & $t(306)=-.97, p=.34$ & \\
\hline Body comparison & .22 & .03 & .41 & $t(306)=7.80, p<.001$ & \\
\hline Step 2 & & & & & .01 \\
\hline $\begin{array}{l}\text { Pre-Menopause x Body } \\
\text { comparison }\end{array}$ & -.08 & .07 & -.08 & $t(304)=-1.06, p=.29$ & \\
\hline $\begin{array}{l}\text { Post-Menopause x Body } \\
\text { comparison }\end{array}$ & -.13 & .07 & -.15 & $t(304)=-1.87, p=.062$ & \\
\hline
\end{tabular}




\begin{tabular}{|c|c|c|c|c|c|}
\hline & \multicolumn{5}{|c|}{ Dietary restraint } \\
\hline & $\mathrm{B}$ & $S E \mathrm{~B}$ & $\beta$ & $t(d f \mathrm{~s})$ & $\Delta R^{2}$ \\
\hline Step 1 & & & & & $.18 * * *$ \\
\hline Constant - reference & 1.29 & .12 & -- & $t(254)=10.47, p<.001$ & \\
\hline Pre-Menopause & -.13 & .17 & -.05 & $t(254)=-.76, p=.448$ & \\
\hline Post-Menopause & .03 & .17 & .01 & $t(254)=.17, p=.867$ & \\
\hline Body comparison & .07 & .01 & .42 & $t(254)=7.25, p<.001$ & \\
\hline Step 2 & & & & & $.03 *$ \\
\hline $\begin{array}{l}\text { Pre-Menopause x Body } \\
\text { comparison }\end{array}$ & .02 & .02 & .06 & $t(252)=.68, p=.495$ & \\
\hline $\begin{array}{l}\text { Post-Menopause x Body } \\
\text { comparison }\end{array}$ & .06 & .02 & .22 & $t(252)=2.67, p=.008$ & \\
\hline
\end{tabular}

\begin{tabular}{|c|c|c|c|c|c|}
\hline & \multicolumn{5}{|c|}{ Body image concerns } \\
\hline & B & $S E \mathrm{~B}$ & $\beta$ & $t(d f \mathrm{~s})$ & $\Delta R^{2}$ \\
\hline Step 1 & & & & & $.01 *$ \\
\hline Age & -.04 & .02 & -.11 & $t(308)=-2.02, p=.044$ & \\
\hline Step 2 & & & & & $.31 * * *$ \\
\hline Constant - reference & 4.22 & .99 & -- & $t(305)=4.27, p<.001$ & \\
\hline Pre-Menopause & -.01 & .18 & -.003 & $t(305)=-.05, p=.960$ & \\
\hline Post-Menopause & .26 & .19 & .09 & $t(305)=1.38, p=.170$ & \\
\hline Body comparison & .10 & .01 & .56 & $t(305)=11.62, p<.001$ & \\
\hline Step 3 & & & & & .003 \\
\hline $\begin{array}{l}\text { Pre-Menopause x Body } \\
\text { comparison }\end{array}$ & .02 & .02 & .07 & $t(303)=1.03, p=.303$ & \\
\hline $\begin{array}{l}\text { Post-Menopause x Body } \\
\text { comparison }\end{array}$ & .02 & .02 & .08 & $t(303)=1.15, p=.253$ & \\
\hline
\end{tabular}

Note. The multicategorical moderator, menopausal status, was dummy coded into premenopause, and post-menopause, with peri-menopause as the reference category (designated 
Constant in the table above). Body comparison is measured by the Body Comparison Orientation subscale of the Body, Eating, and Exercise Comparison Orientation Measure. Broad eating pathology is measured by the Eating Attitudes Test-26. Bulimic symptoms are measured by the Bulimia subscale of the Eating Disorder Inventory. Dietary restraint is measured by the Eating Disorder Examination-Questionnaire. Body image concerns is calculated from a combined score of the Weight Concerns and Shape Concerns subscales of the Eating Disorder ExaminationQuestionnaire. For all continuous constructs, higher scores reflect greater levels of the constructs. $* * * p<.001 . * p<.05$. 


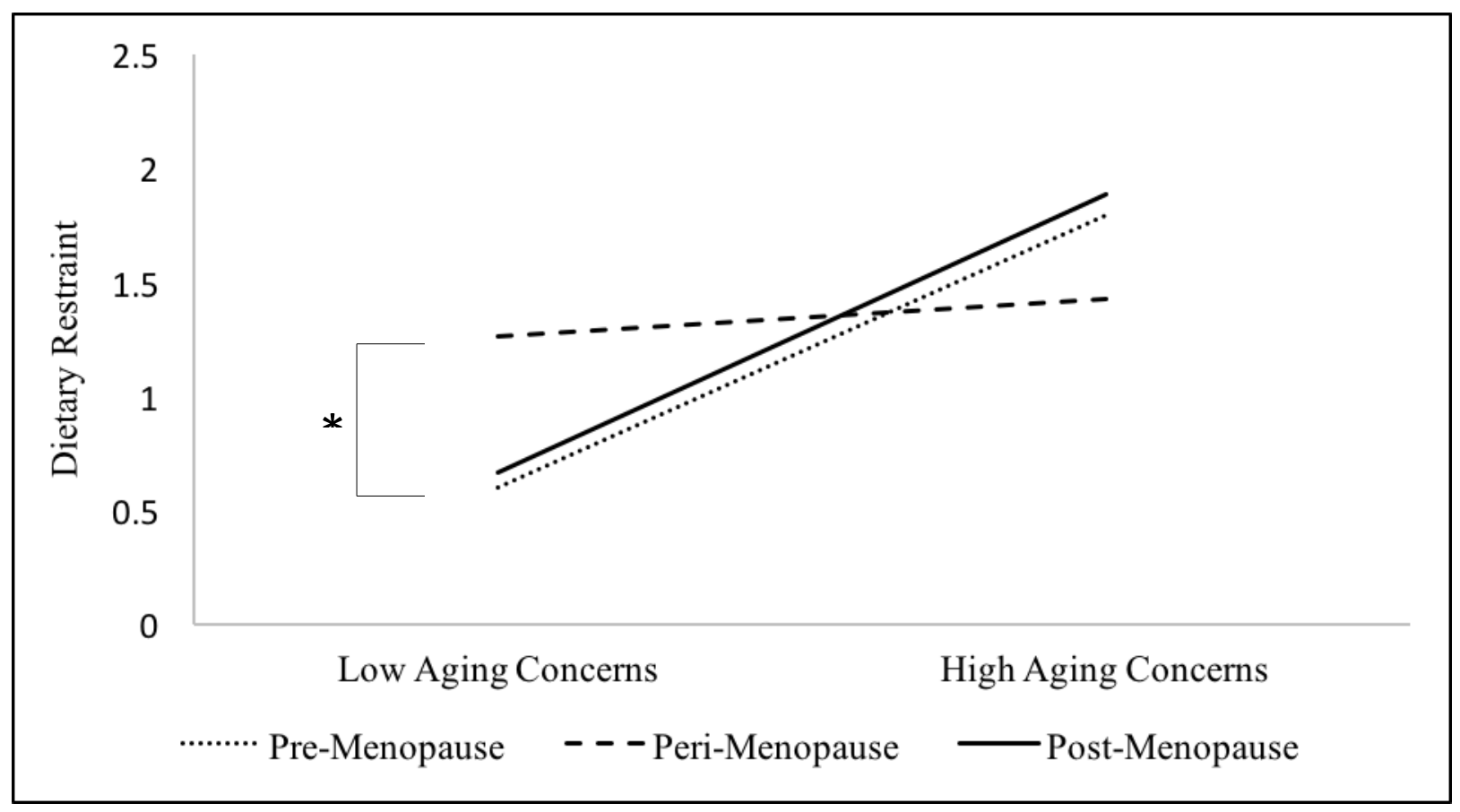

Figure 1. Significant two-way interaction $(p=.005)$ involving negative attitudes about aging moderating the relationship between menopausal status and dietary restraint among middle-aged women. Results show significant differences in dietary restraint between peri-menopausal women and both pre-menopausal women and post-menopausal women when low in aging concerns. $* p<.05$. 


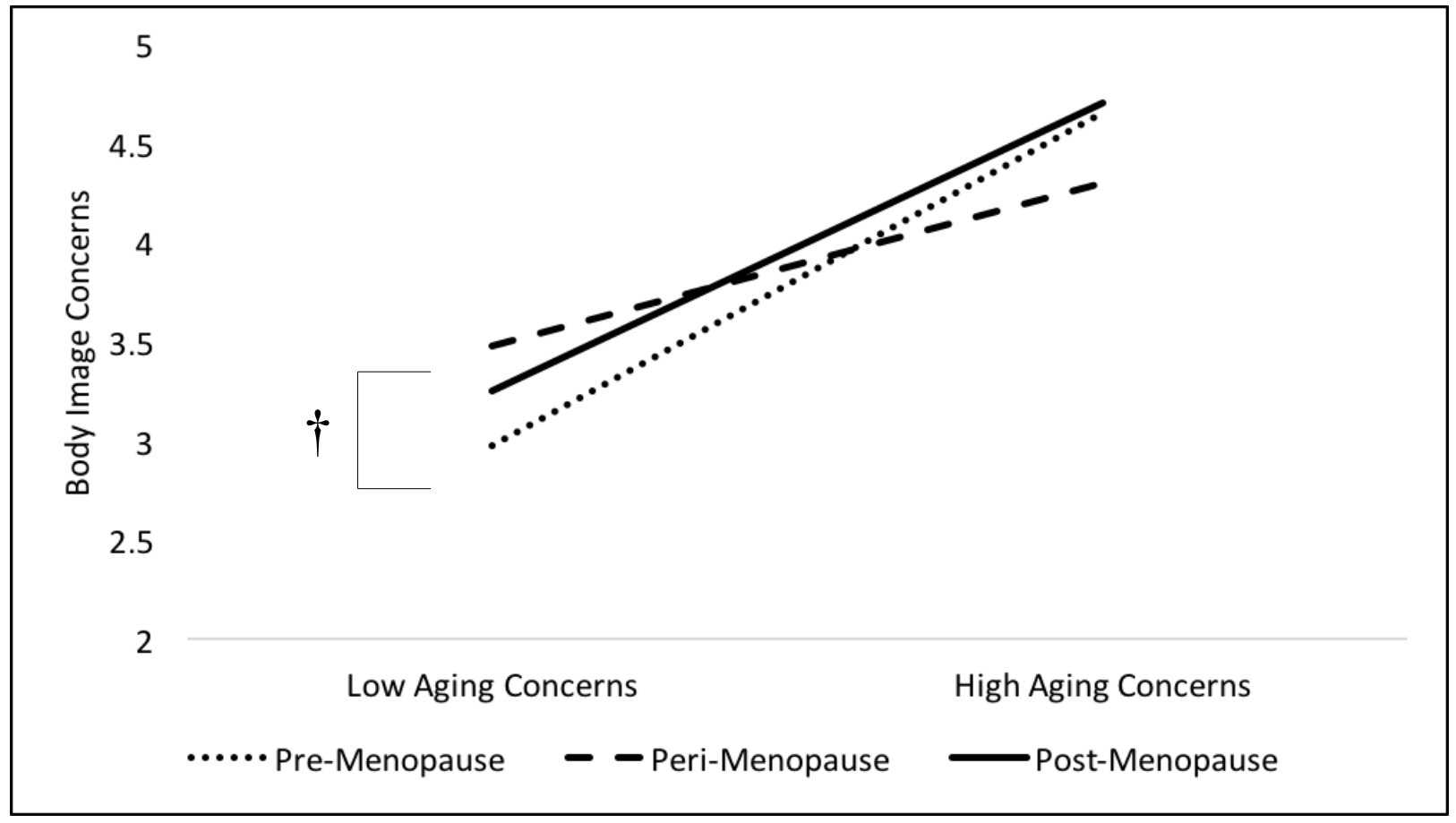

Figure 2. Two-way interaction $(p=.054)$ involving negative attitudes about aging moderating the relationship between menopausal status and body image concerns among middle-aged women trending towards significance. Results show a marginally significant difference in body image concerns between peri-menopausal women and pre-menopausal women when low in aging concerns. $\uparrow<.07$. 


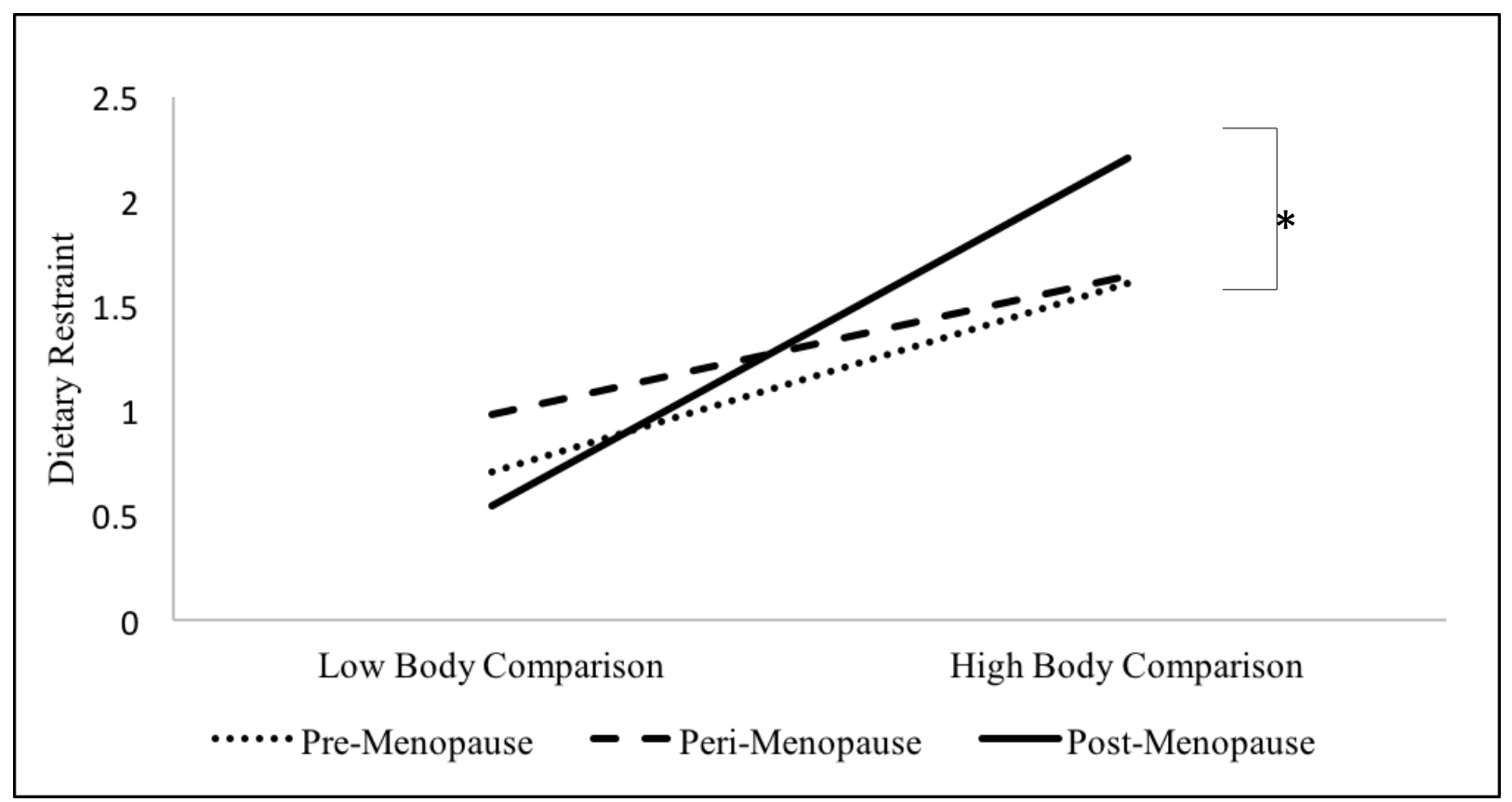

Figure 3. Significant two-way interaction $(p=.021)$ involving body comparison moderating the relationship between menopausal status and dietary restraint among middle-aged women. Results show significant differences in dietary restraint between post-menopausal women and both premenopausal women and peri-menopausal women when high in body comparison. ${ }^{*} p<.05$. 